\title{
Network management and renewable energy development: An analytical framework with empirical illustrations
}

\author{
David Newell*, Annica Sandström, Patrik Söderholm \\ Luleå University of Technology, Division of Social Science, 97187 Luleå, Sweden
}

\section{A R T I C L E I N F O}

\section{Article history:}

Received 29 June 2015

Received in revised form 31 August 2016

Accepted 28 September 2016

Available online 27 October 2016

\section{Keywords:}

Energy policy

Network management

Analytical framework

Renewable energy

\begin{abstract}
A B S T R A C T
The promotion of renewable energy is an essential component of energy and climate policies, but it is increasingly recognized that the transition toward an increased use of renewable energy sources constitutes a complex socio-political process. Policy is manifested in multi-actor networks beyond formal hierarchies and must therefore build on a comprehensive empirical understanding of the local collaboration processes that make investments in renewable energy projects possible. The objectives of this article are to: (a) propose an analytical framework within which the local development processes leading to renewable energy investments can be understood, in particular emphasizing the management of the relevant actor networks; and (b) provide empirical illustrations of the framework based on existing research. The article argues that, based on network management theory, some network structures can be expected to be more successful than others in facilitating renewable energy development, and we recognize the ways in which networks and their structure tend to be placed within certain institutional contexts of rules. By consulting selected research on wind power development at the local level we illustrate the added value of the proposed framework, and outline the seeds of a future research agenda. (c) 2016 Elsevier Ltd. All rights reserved.
\end{abstract}

\section{Introduction}

\subsection{Background and motivation}

An increased use of renewable energy is necessary for a transition towards a sustainable society. For this reason, most developed countries have implemented various types of policy instruments (e.g., feed-in tariffs, quota schemes, etc.) that promote renewable energy development. The social science literature is rich in studies on the aggregate impacts of such policies on capacity developments and technological innovation in the renewable energy sector (e.g., $[28,19,62-64])$. While this research primarily addresses the cost disadvantages of new renewable energy technology and technological lock-in favoring incumbent technologies, previous work has also investigated additional hurdles to renewable energy development, i.e., different legal constraints (e.g., permitting procedures) as well as the importance of stakeholder views and public attitudes in project development (e.g., $[98,77,87,101,48])$. These hurdles often reflect a concern over the negative environmental effects of, for example, wind power as well as a stronger pressure to involve

\footnotetext{
* Corresponding author.

E-mail addresses: David.Newell@ltu.se (D. Newell), Annica.Sandstrom@ltu.se (A. Sandström), Patrik.Soderholm@ltu.se (P. Söderholm).
}

key stakeholders in the relevant decision-making processes (e.g., $[103,44])$.

Most developed countries are characterized by the dispersal of power, not merely upwards and downwards from the national level, but also outwards to quasi-state and non-state actors (cf. $[5,38,49,79])$. Policy is not only associated with administrative hierarchy, it is also formulated and implemented within multi-actor networks beyond formal hierarchies. These networks may involve project developers, contractors, public authorities, researchers, non-governmental organizations etc., and in the case of specific renewable energy projects, many of the relevant interactions take place at the local level. Even though the national government may be active in these networks, policy cannot generally be understood as the product of a single level of governance. On a more normative note, some scholars emphasize that multi-level networks may even be necessary to address complex social challenges in the energy and environment field (e.g., [16]).

Well-designed policies in this field should build on a comprehensive empirical understanding of the prerequisites for renewable energy development as well as the processes leading up to the necessary investments. These processes will be influenced by national policy schemes and goals, but the investments take place in specific local settings, and are therefore also affected by local coordination processes within decentralized actor networks. In fact, the 
joint presence of national goals and support schemes and local coordination processes has sometimes led to a growing disconnect between different levels of governance in renewable energy policy (e.g., [35]), in turn motivating the use of a multi-level perspective in the study of energy sector transformation.

The above suggests that in order to understand - and in turn influence - the processes leading to increased renewable energy development-or the lack thereof-we must study the interactions taking place between various actors at different levels of government and highlight the strategies that can be used to facilitate these interactions. In this article we develop an analytical framework for studying actor networks surrounding renewable energy projects at the local level, how the relevant network processes will be affected by institutional conditions, as well as how the networks can be managed over time.

\subsection{Objectives and approach}

The objectives of this paper are to: (a) propose an analytical framework within which the development processes leading to renewable energy investments can be understood, with a focus on the management of local actor networks; and (b) provide empirical illustrations of this framework based on existing research on renewable energy development. In the latter part, development is defined as the process of planning and installing renewable energy projects (e.g., wind mills) at specific geographic locations. The proposed analytical framework could also be used to analyze actor networks and institutional preconditions in other contexts, e.g., important processes taking place in technological development and innovation systems. Still, our focus is primarily on developed countries, which are typically characterized by relatively stable institutions and some amount of decision-making power at the local level. ${ }^{1}$

In this article we conceptualize the coordinating efforts and processes of a multitude of actors in terms of networks, arguing that some network structures are likely to be more successful than others in facilitating renewable energy development. By adopting a network approach to the study of renewable energy development processes, we can benefit from ideas elaborated on in policy network theory, innovation theory and public network management theory. There are important lessons to be learned concerning both the qualities of networks as well as how to manage the evolution of the networks, i.e., so-called network management. Moreover, we explicitly acknowledge that networks are situated within a given institutional framework, mainly set at the supra-national (e.g., EU) and/or national levels, and explore how the existing institutional arrangements may affect the evolution and the management of the networks.

By doing the above, the article contributes to the existing literature in two ways. First, while the article builds on previous network research, our analytical framework differs from earlier research in that it explicitly recognizes the ways in which networks, and the efforts to manage networking processes, are situated within an institutional (often national) context of rules. Our framework therefore draws on previous research (cf. [54]), yet elaborates more explicitly on the relation between institutions and the various management strategies that can be implemented to influence the networks. In achieving this, the categories of different institutional

\footnotetext{
1 This does not preclude that even developed countries may differ considerably in terms of how much decision-making power the political systems place on the local levels (e.g., the Member States of the EU versus the United States). However, since our framework embraces the roles of both national institutions (institutional design) and the processes within local actor networks (process design), such cross-country differences will not be ignored.
}

rules suggested by Elinor Ostrom and co-workers are adopted (cf. $[69,71])$.

This should permit a clearer empirical understanding of how institutional design - i.e., strategies aimed at changing the underlying rules of collaboration - can affect the prospects for process design - i.e., strategies aimed at influencing the collaborative process itself within the context of the prevailing institutional framework. In the remainder of the article, we introduce a number of key concepts and develop these notions into a coherent analytical framework. This framework also allows us, at least in part, to re-examine the findings from existing studies of the local implementation of renewable energy development, pointing to where the empirics support our framework and suggesting where the use of this framework could have deepened the analysis and understanding of renewable energy development.

Second, while several previous studies of renewable energy development processes highlight the role of actor networks, the empirical analyses of these processes from a network process and network management perspective are generally lacking. ${ }^{2}$ For instance, the technological innovation system (TIS) approach has been used to study energy and sustainability transitions with a focus on networks of actors interacting in a specific technological field under a particular institutional setting, being involved in the generation, adoption, and use of technologies (e.g., [42]). However, while this strand of the literature focuses on a set of innovation processes, it does not devote much explicit attention to how the networks can be managed over time. Despite the focus on actors, institutions and coordination, this work often privileges the structure of the system while downplaying agency and the roles that actors may take in policy-making.

In existing case studies of renewable energy development and innovation processes it is often evident what was done by different actors in terms of promoting (or hampering) increased renewable energy development, but not how it was done. The process by which something is done is at the heart of network management, and neglecting the importance of network processes in the analytical design of research will miss opportunities to understand how these processes can be influenced and ultimately strengthened. For this reason, we use existing research in the renewable energy field to provide empirical illustrations of the potential validity of the proposed analytical framework. These illustrations show how using our framework could have further elucidated the empirical cases in previous studies. It should be noted, though, that these cases are used only as illustrations of the potential of the proposed framework and do not represent a full-fledged review or synthesis of the existing research.

The empirical illustrations focus on the case of wind power, and studies addressing local wind power development processes and the role of actor networks. Wind power represents a key energy supply technology in the transformation to a sustainable energy system, and a wide variety of policies and voluntary efforts exist worldwide to encourage its further development. The wind power industry has witnessed a rapid expansion during the last decades, with declining costs and increasing electricity output. Still, the case of wind power provides a good illustration of the difficulties involved in gaining local acceptance, and of the sometimes growing disconnect between national policy aspirations and local collaboration dynamics (e.g., [35]).

\footnotetext{
2 Giest [35] is a recent exception. Her work focuses on the role of the national (Swedish) government in "managing" and in part "leading" local wind power network structures, although without providing any full-fledged analytical framework Furthermore, Parag et al. [75] adopted a network perspective in the study of energy governance in the UK.
} 


\subsection{Outline of paper}

The next section introduces the network approach, and proposes an analytical framework that can shed new light on renewable energy development processes. In Section 3 we illustrate how the identified analytical concepts could play out in the empirical context of wind power development. Specifically, we provide examples from previous research showing instances of the rules and management strategies that affect wind power development and discuss in what ways the proposed framework could have contributed to an increased understanding of the nature of renewable energy development. Finally, Section 4 concludes the paper by critically reflecting on the added value of the proposed analytical framework and how to develop it further. We also outline the seeds of a future research agenda adopting a network approach in the study of renewable energy development processes.

\section{A network-based analytical framework}

The objective of this section is to outline an analytical framework within which the development of renewable energy and the management of associated processes can be understood.

\subsection{Main elements and motivation}

There is a general trend in society, policy and research towards networks and networking. The complex nature of contemporary problems is causing the formation of collaboration structures or networks spanning horizontal sectors as well as vertical borders $[2,49,54,97]$. Policy programs often (explicitly or implicitly) entail a network approach, thus promoting the evolution of various actor networks, sometimes referred to as collaborative management structures, public-private partnerships, Triple-Helix structures, etc. Renewable energy development processes engage a multitude of actors in cross-sector collaborations, e.g. wind power developments (e.g., [98]); bioenergy processes [67] and offshore wind power developments [55].

In policy studies, the network concept has been considered not only a growing empirical phenomenon but also an analytical lens through which policy-making processes can be understood $[37,21,59,86,96]$. In this light, the constellation of actors-forming social networks around specific policy problems-becomes a relevant analytical unit to explore in the study of policy making and in the search for explanations for policy outcomes.

Networks reflect structures of resource exchange and negotiation among interdependent actors $[15,32,80]$. This is evident in the case of renewable energy development. New projects require resources, e.g., funding, knowledge/competence and public support, which, in turn, require regular interactions between investors, decision-makers and local stakeholder groups. The attributes of actors-e.g. their interests, objectives and resources-influence the outcomes of collaboration (cf. how R\&D actors influenced the trajectory of innovation in [100], but so do the ways in which actors are linked to one another. Thus, the web of resource exchange and negotiations constitutes an important analytical unit, in particular when research aims at understanding the outcomes of collaboration [12,53,59,91,45]. Parag [76] used a network perspective to analyze and explain the formation of industrial emission policy in Israel. In another study Parag et al. [75] analyzed local energy governance in the UK through the network lens. Devine-Wright [29] emphasized the role of social networks in understanding public perceptions on wind energy projects. In this article, we attribute a broad explanatory power to networks in the study of renewable energy development.
The establishment of collaboration is not a straightforward process [94]. Jacobsson and Johnson [43] and Giest [35] argue that poor connectivity in innovation networks may give rise to failures to adopt new renewable energy technologies. Verbong et al. [100] describe how network tensions are built up by clashes between developers and utilities in the development of renewable technology. Besides scarce resources, various uncertainties regarding the strategic choices made by the actors involved, and the overall institutional framework, need to be addressed within network collaboration (e.g. [54,92]). Increases in transaction costs and broken agreements are two examples of potential complications (e.g. [1]). Actors normally represent different sectors and act according to different organizational logics [104]. We can expect them to have different policy beliefs-i.e. ideas about the policy problem and its possible solutions-and form coalitions with likeminded actors to influence the policy process (see also the ACF-framework [88,102]). Coalitions, either for or against wind power development, often emerge at the local level and the interplay between these coalitions can have significant impacts on development processes [95].

While other analytical frameworks risk missing important actors and actions not formally attached to the renewable energy development process, the network approach helps to identify and delineate the relevant unit of analysis empirically using a bottom-up methodology and considering formal as well as informal relationships.

\subsection{Network features influencing outcomes}

Assessments of network outcomes address how well the network deals with any associated challenges and how it manages to create win-win structures among the actors involved. Network effectiveness is about the added value of collaboration [83]. Bryson et al. [15] discusses network outcomes in several orders; from partnership agreements and the evolution of new institutions to joint learning and changes in practices. Donahue [30] identifies three criteria for evaluating cross-sector collaborations: first, the establishment of collaboration; second, how collaboration meets the organizational objectives of the partners involved; and third, to what degree collaboration outperforms alternative arrangements.

There is no blueprint for effective networks. Even so, there are theoretical arguments $[11,22,23,34]$ as well as empirical support that indicate that certain network features influence network performance (e.g., $[26,40,39,61,74,81,82,91,93])$. The network approach has thus moved from being merely a descriptive metaphor (cf. $[25,46])$ to becoming an explanatory variable in contemporary policy research.

One important network feature has already been mentioned here, namely heterogeneity, i.e. actor diversity. Structures composed of a heterogeneous set of actors (e.g., with different organizational affiliations) are more successful in securing necessary resources (e.g., competence, public support etc.) and sustaining innovative capacity. These structures are assumed to encompass bridging ties connecting the network to other critical organizations and clusters (cf. $[18,17,34,13,6,56])$. For instance, wind power-based collaborations that lack representation from local environmental protection groups may struggle with legitimacy issues; a network that is not anchored among political representatives might encounter severe problems in getting permissions, political support, etc.; a network excluding local businesses might fail to secure supplies of products or services. In the context of renewable energy, different types of benefit-sharing instruments (instruments that transfer benefits to local communities) are often introduced to build bridges among actors and to improve the social acceptance of projects (e.g., [31]).

The level of integration is frequently stressed as another network feature that influences the collaboration process. This feature 
is often assessed by how densely connected and centralized a network is, and it is assumed that networks with many connections and a clear coordinating unit are better equipped to define common problems and to prioritize among those problems $[81-83,17,91,4]$. Some countries (e.g., Italy) have strived to achieve a more centralized licensing process for new electric power plants, thus providing space for a coordinating central function [41]. The renewable energy development process in most countries, however, should be understood as a largely local process lacking a central coordinating actor. There is normally no central actor controlling renewable energy development processes; instead these occur through multi-level and multi-actor collaboration. In this context, network integration matters for how the actors (e.g., investors, the local communities etc.) interact, exchange resources and form a common agenda.

Finally, stability (e.g., reflected by prior relationships, durability and level of formalization) is emphasized as an important network feature influencing outcome by, for instance, reducing uncertainty $[15,74]$. The levels of predictability, trust and actors' willingness to share resources are likely functions of network stability. Accordingly, development of wind power might be easier in areas with high rates of existing wind power penetration due to the presence of well-established networks and institutional structures, e.g., legal rules and informal norms (e.g., [43]).

While other frameworks put emphasis on structure or agency, the network approach combines both based on the notion that the qualities and the patterns of relationships (i.e., the exchange of resources and coordination) - the network structure - have important effects on individual behaviour and collaboration.

\subsection{A managerial approach to networks}

Given the central role of networks in renewable energy development, the issue of how to influence the evolution and features (i.e. heterogeneity, integration and stability) of these structures becomes imperative. Accordingly, the topic of network management has gained increased attention in the public management literature (e.g. [60,54,73,85,49,72]). Koppenjan and Klijn [54] describe network management as the actions taken to further the interactions in networks. For the purpose of this article, we define network management as deliberate attempts (e.g., by municipalities, project developers) to manage collaboration networks. The network manager influences or controls the collaborative process by means of one or several management strategies. Previous studies imply that both the amount, as well as the types of strategies used, affect outcome (e.g. $[50,73,90,89])$.

The common denominator of existing typologies describing network management strategies is that they separate between strategies directed towards: (a) the network structure; (b) the network substance; and/or (c) the network process (e.g. [3,33,54,52,50]). Klijn [51] additionally separates between strategies aimed at changing the underlying rules of collaboration, i.e., institutional design, and strategies aimed at influencing the collaborative process within the prevailing institutional framework, i.e. process design. We adopt the typology above and argue that the separation of institutional design and process design is necessary for disentangling different ways to manage collaboration networks in the renewable energy sector.

\subsubsection{Institutional design}

Networks are placed within an institutional context of rules that define the basic conditions for collaboration within renewable energy development processes and influence how different challenges are dealt with, including the possibility of realizing winwin situations $[68,69]$. The number of institutions that shape the characteristics of collaboration networks is vast and complex. Net- work management of renewable energy processes via institutional design entails specifying the rules that influence the network structure, substance and process. These strategies are presented below, borrowing from the typology of rules proposed by Ostrom and Crawford [70].

Network structures are influenced by adjustments in boundary rules and position rules. These rules define what actors should have access to the process, as well as what their respective positions within that process are. Legal regulations requiring stakeholder participation in the wind power planning process are an example of these rules.

The network substance around which the network is formed, and what issues can be handled within the process, is dependent upon the prevailing scope rules. These rules define the scope of potential outcomes and can be exemplified by regulations concerning what areas are considered suitable for wind power, as well as by energy output targets for wind power. Variations in scope rules explain, in part, the differences in wind power development across the Nordic countries. The Danish directive stipulates that areas suitable for windmill establishments should be designated and included in regional planning guidelines, while the corresponding Swedish legal rules have less legal strength [77].

Several rules influence network processes. Choice rules set the boundaries for what actions are required, permitted or forbidden, an example being the regulations concerning licensing procedures (including environmental impact assessments) for new wind power projects. Aggregation rules set the terms for power and control by determining decision-making procedures. A critical feature of the national regulations for wind power concerns the question of how political power is allocated between national, regional and local decision-makers. There are important differences across countries, although systems that grant local authorities substantial discretion in influencing permitting processes for wind power are the most common [41]. The networking processes are also affected by how the access to and diffusion of information is regulated (information rules) and by existing pay-off rules, which associate certain actions with benefits and costs, thus affecting the incentives to participate in the process. Different government subsidies, support schemes and compensation mechanisms clearly fall into this latter category, and the role of these policy instruments has been addressed extensively in previous studies on renewable energy development [19]. The concept of managing renewable energy development networks via institutional design implies a need to elaborate all the above-mentioned rules.

\subsubsection{Process design}

In addition to institutional design, network managers' engagement in influencing process design is important for network outcomes. Klijn $[51,50]$ lists four different types of process design strategies. ${ }^{3}$ Unlike institutional design strategies, process design strategies build on the assumption that the institutional structure is set (i.e., exogenous), and focus on how a network's structure, substance and process can be influenced within the prevailing context of rules and management-control measures. Thus, network managers' actions aimed at influencing the design of the network process, without altering the fundamental rules, fall within this category.

The first such strategy, activation/deactivation of actors and resources, aims at influencing the network structure and includes efforts to engage or exclude certain groups or resources from the process [51]. By doing so, the network manager can ensure that the necessary resources, such as money, competence, knowledge

\footnotetext{
${ }^{3}$ Klijn applies the concept of process management and uses slightly different terminologies in his papers.
} 


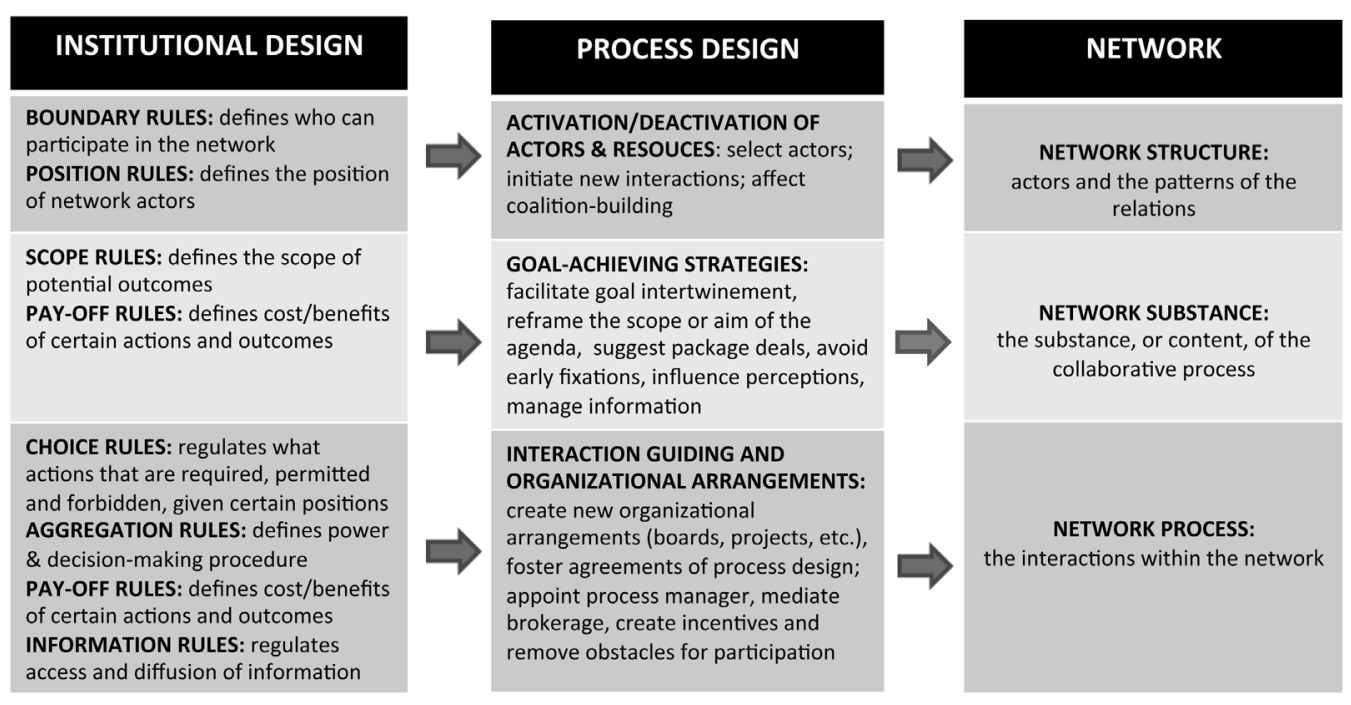

Fig. 1. How Institutional and Process Design Influence Different Components of Networks.

or legitimacy are available. Efforts to encourage new interactions, build coalitions, and stabilize the network are also included in this category.

The second type of strategy includes goal-achieving strategies, which encompass attempts to facilitate goal congruency and goal intertwinement among the involved actors [51]. This is particularly relevant in situations characterized by conflicting interests and opposing coalitions, and can be done by reframing the process-i.e. reformulating the problem and the agenda to more appropriately correspond with the goals and interests of key actors-by, for example, presenting a new wind farm as a local development project and thereby enlarging the coalition in support of the project. Network managers can also present package deals, which combine seemingly incompatible goals such as economic development and conservation, and work with multiple objectives. In addition, a lot can be done to influence and explicate the involved actors' perceptions, through, for example, the dissemination of new information and knowledge.

The third and fourth strategies suggested by Klijn [51] are organizational arrangements and interaction guiding, respectively. Network managers can influence how the development process is organized, sustaining cross-coalition negotiations by, for instance, introducing different projects adjacent to the process, initiating the formation of boards or working groups, and by adopting roles as mediators. These strategies aim to create initiatives and remove obstacles for collaboration, and since these primarily influence the network process, we will discuss them together.

Other frameworks, building on a traditional approach to public management, depart from formal institutions and the political-administrative system, assuming the primacy of politics in controlling and designing the policy process. Given the characteristics of renewable energy development processes it is probably fair to conclude that traditional frameworks to management may fail to account for critical elements and dynamics of the development process.

\subsection{How institutional and process design influence networks}

Fig. 1 is based on the theoretical discussion above; it summarizes the institutional and process design strategies and illustrates how these are assumed to influence different components of networks.

The arrows in Fig. 1 imply a hierarchical relationship between institutional design and process design, in which the former defines the conditions for the latter. The institutional arrangements are the basis for the fundamental characteristics of the action arena and, by means of institutional design-e.g. changes in boundary rules, position rules, etc.-collaboration can be altered. However, due to the institutional interplays, and the impacts from various contextual factors, similar institutional designs do not necessarily give rise to similar results. The acting space within a given institutional setting is significant and the collaboration networks can be further influenced via process design strategies, such as the activation of actors and resources or by adopting various goal-achieving strategies. Therefore, the link between institutional design and the network goes via process design strategies (Fig. 1).

It could be argued that the relationship between institutional and process design could go in both directions. The time required, however, for process design elements to affect institutional design is likely significant. Furthermore, since there are likely multiple local networks governed by a given institutional design, it is not certain whether the effects in all of the networks would be uniform. Fig. 1 should be considered as an analytical framework-a heuristic device-organizing empirical analyses in the search for deepened understanding of how different rules and network management strategies influence collaboration. Obviously, it is a simplified description of a significantly more complex reality, which could be revised, depending on what relationships a given analysis should focus on.

Fig. 1 further illustrates that the various network management strategies affect different network components. This is an important contribution of the framework. To exemplify, starting with the top row in the figure, it can be assumed that the network structure is primarily influenced by boundary and position rules, as well as network managers' strategies of mobilizing or excluding certain actors. This means that, for example, the levels of network heterogeneity previously identified as important for the performance of renewable energy processes, can be affected by means of these strategies. According to the same reasoning, network managers can elaborate on the scope and pay-off rules, respectively, and make use of various goal-achieving strategies-e.g. reframing the purpose of the wind power process-in order to influence the substance of the network (middle row in Fig. 1). Finally, several types of rules influence the features of the network process (last row in Fig. 1), e.g., the aggregation rules that define power relations and procedures for decision-making and choice rules that stipulate required or permitted actions. The network manager can also adopt an assortment of different process design strategies to affect the interactions among the actors. 
Table 1

Managing Wind Power Development via Institutional Design - Empirical Examples.

\begin{tabular}{|c|c|c|}
\hline Network Structure & Network Substance & Network Process \\
\hline $\begin{array}{l}\text { Boundary Rules: } \\
\text { - The extent to which decisions are } \\
\text { located at the national, regional or } \\
\text { local levels, as well as include and } \\
\text { exclude certain actors }[47,78] \text {. }\end{array}$ & $\begin{array}{l}\text { Scope Rules: } \\
\text { These rules may stipulate: } \\
\text { - the designation of areas for the } \\
\text { development at the national, } \\
\text { regional or local level }[47,77] \text {; } \\
\text { - how the plannning process and }\end{array}$ & $\begin{array}{l}\text { Choice Rules: } \\
\text { - These rules may stipulate the range } \\
\text { of decisions delegated to actors in } \\
\text { the planning and permitting } \\
\text { processes }[27,47,65] \text {. }\end{array}$ \\
\hline $\begin{array}{l}\text { Position Rules: } \\
\text { These rules may stipulate: } \\
\text { - the roles assigned to various actors } \\
\text { in the planning process; } \\
\text { - who is involved in the }\end{array}$ & $\begin{array}{l}\text { benefit determinations are } \\
\text { regulated, e.g. whether they are } \\
\text { integrated or separated and what } \\
\text { actors are involved in each [27]. }\end{array}$ & $\begin{array}{l}\text { Aggregation Rules: } \\
\text { - These rules may involve regulations } \\
\text { governing the permitting procedure, } \\
\text { ownership, and the degree of } \\
\text { delegation of authority for decisions }\end{array}$ \\
\hline $\begin{array}{l}\text { determination of benefits; and } \\
\text { - how the determination of benefits is } \\
\text { related to planning processes [27]. }\end{array}$ & $\begin{array}{l}\text { Pay-off Rules: } \\
\text { - These may include benefit-sharing } \\
\text { agreements, feed-in tariffs, green } \\
\text { certificate schemes, and beneficial } \\
\text { tax status. These rules also affect the } \\
\text { network process }[63,84,9,44,99,31] \text {. }\end{array}$ & $\begin{array}{l}\text { to planning process/local level [9]. } \\
\text { Information Rules: } \\
\text { - These include public participation } \\
\text { and consultation requirements, e.g., } \\
\text { in meetings connected to the } \\
\text { planning process [35]. }\end{array}$ \\
\hline
\end{tabular}

In the next section, we illustrate how the strategies presented in Fig. 1 may play out in the empirical context of wind power development. Empirical examples from previous studies are used to illustrate the value-added of a network approach and to exemplify various network management strategies. National-level and government institutions reflecting institutional design strategies, as well as process design strategies adopted by network managers at the local level, will be presented. This is not to imply, however, that the two categories, by necessity, occur at certain administrative levels.

\section{Illustrating the empirical relevance of the framework: examples bases on previous research}

In this section we illustrate the empirical salience of the framework proposed in this article. The section will also demonstrate how the framework-especially the part dealing with process design-would have elucidated factors that were missed in previous studies that employed other frameworks. Because, as noted earlier, management by means of institutional design has already received significant and explicit attention in previous research, the examples for institutional design are more concise and not designed to illustrate gaps in the literature so much as to provide general support for the institutional design portion of our framework. On the other hand, the examples of management by means of process design will be emphasized somewhat more and be evaluated more critically in order to illustrate points-missed by previous research.

\subsection{Management by means of institutional design}

The existing literature on wind power development contains many examples of institutional framework factors-policy and policy instruments-that affect network structure, substance and process through changing the rules of the game. It should be noted that various policies often end up creating multiple types of rules, e.g., policy instruments that stipulate the inclusion of certain actors in the planning process could affect scope rules, boundary rules and choice rules. Table 1 summarizes a number of ways in which institutional design has been found to affect the network process in the context of wind power development.

Network structure is affected by measures that create boundary rules defining who can participate in the network. These measures often come from the top-down, i.e. the national government. Clear examples of boundary rules are rules governing participation and authority in the planning processes. In the Nordic countries, for example, at a general level the different wind power planning processes are seemingly comparable. They are decentralized, with several planning levels, but there are some important differences in the implementation process. In the Danish system planners cannot ignore national-level policy objectives and directives [78]. In contrast, the Swedish rules essentially grant a monopoly over the local planning process to municipalities [47], clearly delineating networks in a way that excludes, or at least significantly reduces, the influence of national government actors. ${ }^{4}$

An example of position rules, which determine what roles different actors play in a network, is in the United Kingdom (UK). In the UK, the local planning process and the determination of municipal benefits from wind parks are, by law, kept separate so as to avoid bias in the planning process [27]. While a diversity of actors may be involved in the network surrounding a wind power project, the actors involved in the planning process are in the position of determining which projects will go forward or not, and those who negotiate the distribution of benefits are placed in a "secondary" position of power. Position rules also provide for - and increasingly encourage - groups of stakeholders to participate actively in the relevant decision-making processes through consultations, partial ownership etc. Countries may differ in the extent to which they acknowledge the involvement of local actors, both with respect to the opportunities to influence decision-making and as owners of projects. For instance, starting as early as 1979 , it was possible for small, private investors in Denmark to obtain public financial support for wind power projects; in Sweden this was not possible until 1992.

Scope rules designate specific areas for wind power development, as well as at what level such designations are made. In Sweden, for example, these are determined at the national and regional levels, whereas in Denmark they are determined more locally [76]. Another example of scope rules is the UK, where the wind power planning process is separated from the process of determining the distribution of local benefits from wind power development [27].

Pay-off rules include traditional policy support schemes, such as feed-in tariffs, green certificate schemes and tax advantages

\footnotetext{
4 Similar differences in the territorial planning procedures exist also in other countries. For instance, France also has a relatively decentralized system [65], while Italy has introduced a more centralized planning process for electric power plants [41].
} 
Table 2

Managing Wind Power Development via Process Design - Empirical Examples.

\begin{tabular}{|c|c|c|}
\hline Network Structure & Network Substance & Network Process \\
\hline $\begin{array}{l}\text { Activation/Deactivation of } \\
\text { Actors/Resources: } \\
\text { - programs to involve local actors } \\
\text { across various sectors in the } \\
\text { development process [14]; } \\
\text { - "participative planning", i.e. } \\
\text { involving a diversity of actors in the } \\
\text { planning process specifically [14]; } \\
\text { - formation of cross-sectoral advisory } \\
\text { groups and committees [24]; } \\
\text { - reaching out to help actors preempt } \\
\text { or resolve differences [44]; } \\
\text { - encouraging wind developers to } \\
\text { consult with the affected local } \\
\text { communities [36]; } \\
\text { - government-appointed wind power } \\
\text { network managers [35]. }\end{array}$ & $\begin{array}{l}\text { Goal-Achieving Strategies: } \\
\text { - defining broad and commonly } \\
\text { shared goals [24]; } \\
\text { - "inclusive project planning" [14]; } \\
\text { - early, local financial participation } \\
\text { and local co-ownership [14]; } \\
\text { - alliance between developers and } \\
\text { certain local actors in favor of wind } \\
\text { power [44,35]; } \\
\text { - alignment of "mobilizing } \\
\text { discourses"/"discourse coalitions", } \\
\text { i.e. bringing together actors with } \\
\text { similar beliefs [95]. }\end{array}$ & $\begin{array}{l}\text { Interaction Guiding and Organizational } \\
\text { Arrangements: } \\
\text { - joint-ownership between municipal } \\
\text { energy companies and local owners } \\
\text { of wind power [47]; } \\
\text { - collaborative committees comprised } \\
\text { of government, developers and local } \\
\text { communities [36]; } \\
\text { - meetings between developers and } \\
\text { municipalities to mediate and } \\
\text { resolve disputes and coalesce } \\
\text { around goals [44]; } \\
\text { - organizations created that include } \\
\text { actors from across private, public } \\
\text { and civil society sectors, as well as } \\
\text { different levels and units of } \\
\text { government [66]. }\end{array}$ \\
\hline
\end{tabular}

(e.g., $[63,84])$. Pay-off rules also concern mechanisms ensuring local benefit-sharing from wind power projects as exemplified in Denmark, Germany, France, the United Kingdom and the USA $[9,44,99,31]$. These mechanisms include land lease payments, the promotion of local ownership, property taxes, taxes on wind power revenues, etc.

Choice rules determine what actions are required, permitted and forbidden, as well as which actors can take certain actions. An example of this is the delegation of authority for wind power planning to the local planning process, where municipal and other local actors are authorized to undertake a range of decisions concerning wind power development. Choice rules are also evident in the local planning and negotiation processes, where approval for certain actions-for example, whether, how and where private actors can build wind turbines-that promote or hinder wind power development is given, such as in the UK, Sweden and France $[27,47,65]$.

In terms of aggregation rules, which regulate decision-making procedures, as well as who has power in a given system, the clearest examples are often found in the legislation regulating the permitting procedures for wind power. Important components include the territorial planning requirements, but also the system of rules governing the assessment of the environmental impacts of wind power projects. As noted above, legislation may also set boundaries for how different actors are permitted to collaborate in developing wind power. Denmark is an interesting case, where "wind partnerships" (a form of local cooperative arrangement where turbine owners are also consumers of the electricity produced by the group) may be formed to develop wind farms and sell the electricity to local energy companies. Such arrangements have been the only type of cooperative ownership agreement allowed by law, aggregating the decision-making power for wind power development within such partnerships (see [9]).

Information rules regulate the access to and diffusion of information to local stakeholders e.g., through hearings, consultations, etc. These information forums can be important in influencing acceptance of new wind power projects with wind power developers sometimes even taking additional, voluntary action to provide locals with opportunities to voice concerns. An example of this is in Sweden, where the government established a "National Network for Wind Power" [35], which has, among other responsibilities, a directive to disseminate information concerning wind power to promote local-level acceptance and amenability to planning for wind power at the municipal level.

\subsection{Management by means of process design}

Within a given institutional framework, networks play an important role in affecting policy outcomes. Even with welldesigned policy instruments, whether wind parks actually get built or not depend to a great extent on local networks comprising developers, municipal officials, citizens, advocacy groups, etc. Network management strategies that affect process design aim to affect the structure, substance and process of networks. The following section contains examples from articles and reports that point to the presence of such strategies and, as is often the case, how the use of a network management framework, such as the one proposed in this article, would have deepened and expanded the analysis of the examples. While it is not possible to examine empirical evidence that was not collected as part of these studies, it is often evident that network management strategies were employed in these cases. Table 2 summarizes a number of ways in which process design has been found to affect the network process. As with the empirical illustrations in Section 3.1, the examples of strategies employed in this section sometimes affect multiple parts of the network. For example, a strategy that creates a new organization facilitating interaction between wind power developers and local actors not only creates an organizational arrangement; it also activates actors and facilitates goal alignment.

The case of the German State of North Rhine Westphalia (NRW) demonstrates how network management strategies can affect network structure through activating or deactivating actors and resources. In order to facilitate the development of wind power in the state, the NRW government adopted programs to reach out to businesses, municipalities, households and individuals in an effort to involve them in the development process, thereby increasing social acceptance [14]. These programs activated actors that might have otherwise stood on the sidelines until they felt their interests were threatened. A theoretical focus on network management would, in this case, have explicated the role the activation of actors and resources played in the development process, as well as capturing other such strategies employed by actors that were not included in the official programs and planning process.

Another example of this management strategy is the Wales Assembly Government's (WAG) approach to wind power policy formation, including the creation of advisory groups comprising actors from the public and private sectors and civil society (e.g. environmental groups) [24]. These advisory groups brought actors into the policy network, thus changing the structure of the network. Had a network approach been used in this study, the role of these advi- 
sory groups, in bringing different perspectives to the policy process and offering arenas for cross-sector negotiation, would have been examined at the outset of the study, instead of as an aside.

Deliberative strategies to involve (sometimes conflicting) civil society groups with developers and public-sector officials in the wind power planning process have also been noted in French cases. In one study, which analyzed the factors that affect the social acceptance of wind power, public officials reached out to disparate groups-a bird association and a hunter's group-to resolve differences and unite in the planning of a wind park [44]. By reaching out to actors and involving them through helping to resolve and preempt disputes, this strategy affected the network structure and the social processes within. A network approach would have drawn attention to how and why the strategy of activating actors was important, and its influence on outcomes, perhaps leading to different conclusions from the Jobert study, which emphasized institutional and territorial factors.

Another approach to actor activation is exemplified in the state of New South Wales, Australia. Here the state government encouraged wind developers to consult with affected communities throughout the development process, an example of indirectly affecting collaboration among actors and the network structure [36]. The regional government also established committees involving cross-sectorial actors to provide communities with additional means of communication and coordination regarding wind power development, an example of the institutionalized activating of actors. Hindmarsh discusses the importance of community engagement, yet this highly empirical study fails to place community engagement within a broader theoretical context that would explain why community engagement is an important strategy. The framework proposed in our article would do just that.

The "National Network for Wind Power" in Sweden [35] is another example of the activation of actors and resources. Government designated network managers, known as "National Wind Coordinators," were given the responsibility of facilitating "interaction between wind power developers, government agencies, [and] research and other stakeholders at the national, regional and local level" [35]: 5-6). In this way, actors from multiple sectors were brought together to consult with one another and to resolve differences, a clear case of how network management can benefit the performance of networks. Giest explicitly uses a network approach and thus benefits from a clear understanding of the importance of affecting the policy process through actor activation.

An interesting case of goal-achieving strategies, the set of network management strategies that affect network substance, is a study on Wales. When confronted with conflicting views about which renewable energy technologies to develop, WAG ministers showed political leadership and set an electricity generation goal around which actors were able to coalesce (e.g., [24]). By reframing the debate and defining the scope broadly, goal intertwinement was facilitated, an effective goal-achieving strategy. The Cowell [24] study took a governance and planning approach to understanding wind power development. However, had there not been an explicit goal formulated by the government, it would have been possible to neglect the importance of goal-achieving strategies in facilitating the policy outcome.

Another example of goal-achieving strategies can be found in the Netherlands, where "cooperatives [took] up locally inclusive project planning and other independent, applied, local ownership and inclusive project planning," with the goal of finding appropriate local sites for wind turbines ([14]: 2743). However, because these arrangements were not institutionalized and there was not a tradition of national engagement of the local level, the initiative floundered. Inclusive project planning facilitates goal-achieving through bringing actors together for a common purpose, i.e., deciding the allocation of land and enabling goal-intertwinement.
Viewed through the lens of managing networks for process design, the significance of such strategies in the policy process comes to the fore.

Goal-achieving strategies are also highlighted in the case of Germany where, "the importance of early, local, financial participation or co-ownership was emphasized in NRW by those who had been involved in wind power development since the beginning years," ([14]: 2740). Co-ownership is a common means of facilitating goal intertwinement, with financial benefits to the community from wind power becoming a common rallying point for actors from diverse sectors, with diverse interests. Programs set up to activate various actors in the planning process also facilitated goal intertwinement because actors had a forum to discover potential goal alignments through negotiation and discussing potential winwin situations [14]. While the co-ownership programs are a good example of goal-achieving strategies in this study; a network management perspective would have emphasized the importance of such arrangements for affecting policy outcomes.

Another example of a goal-achieving strategy is the case of France, where a policy aimed at allying wind power developers with some local wine growers, resulted in goal intertwinement between these groups, while isolating other wine growers that might have opposed the development [44]. The wine growers who allied with the wind developer cooperated in providing tours of the local area that included both the wind park and their fields. Jobert et al. define such actions as "site-specific conditions" but do not explain the theoretical underpinnings of these conditions in relation to policy networks or outcomes, rendering the analysis more empirical and ad hoc. The case is in fact an excellent illustration of how network managers can alter the structure of coalitions via goal intertwinement.

Another example of facilitating alliances between actors is found in the case of The National Network for Wind Power in Sweden [35]. The networks facilitated the defining of broad and common goals through bringing developers, government agencies, local actors, etc. together to consult with each other and to cooperate and coordinate action. This case, which was studied explicitly from a network perspective, illustrates the importance of networks in bringing actors together to better understand each other and find goal alignments.

A study on the case of France provides an interesting example of where goal-achieving strategies were not used, yet likely had an impact on policy outcomes. In addressing why there was not a "wind power rush" in France following the implementation of a feed-in tariff scheme, as there had been in other countries, Szarka [95] references the importance of "mobilising discourses" and "discourse coalitions." Discourses, in this case, are essentially ways of framing policy issues and illustrate how actors conceive of their goals. Through policy learning, i.e., goal intertwinement, reframing the scope and agenda, and influencing perceptions, alignments can be made and differences in how goals are conceived can be preempted. Here it can be argued that a lack of goal-achieving strategies aimed at goal intertwinement, reframing the scope and agenda, and influencing perceptions, led to a failure to see the wind power development realized by other countries. This emphasizes the critical importance of assessing the use-or lack of use-of goal-achieving strategies in explaining the renewable energy policy process and outcomes.

In regard to strategies that facilitate the guiding of interactions and the establishment of organizations (i.e., that affect network processes), wind power planning in Sweden provides an interesting example. In the Swedish municipality of Falkenberg, local officials encouraged and supported local ownership of wind turbines. Local actors, including companies and individuals, were given the opportunity to buy shares in a joint-ownership arrangement [47]. Through establishing organizations for joint-ownership of wind 
farms, a forum for interaction between wind developers and local actors was created. While formal organizational arrangements are often described in studies of wind power development, less formal, behind-the-scenes arrangements, interaction guiding, fostering agreements, etc. are less likely to be accounted for in the analysis of cases of wind power development unless a network management approach is taken.

In the case of Australia, a collaborative approach to wind power development between the federal government, developers and communities led to staffed committees being established to facilitate the interaction of actors with diverging interests and to mediate and mitigate disputes regarding wind power development [36]. By taking a collaborative approach and establishing committees, interaction guiding was facilitated through creating organizational arrangements. Such arrangements also led to goal intertwinement and therefore affected the network substance as well as the network process. A network management approach facilitates a theoretical understanding of such strategies, in addition to examining less formal means of interaction guiding perhaps not taken into account by this study.

A local case in France also offers an example illustrating interaction-guiding. The study by Jobert et al. [44] showed how the municipality and the developer arranged meetings to mediate disputes between various actors that could have otherwise led to opposition to wind power. The meetings also provided a forum for coalescing around common goals. Furthermore, a new company was proposed by the mayor of the municipality in order to rally support from other local officials. The result was a favorable local disposition toward the wind power development, and the isolation and minimization of opponents to the project. The strategy used here affected the network process through the creation of an organizational arrangement within which interaction guiding could occur and also activating/deactivating actors. This led to increased goal intertwinement, which affected network substance as well. This case demonstrates the importance of understanding not just what was done in the process, i.e., what policies, incentives etc. were used, but also how the process was conducted, i.e. what strategies were, or were not, used.

A final example comes from a study by Nadai and Labussiere [66], which examines wind power development in the region of Aveyron in southern France. As wind power development took off in the region, a new organizational arrangement was created, including both government agencies dealing with roads and infrastructure, environment, industry, cultural heritage, as well as non-administrative entities such as a bird watchers organization and the Regional Park and government entities. This arrangement was further complicated by a national planning framework for the decentralized planning (i.e., by local authorities) of wind power developments. The study concludes that the success of the national planning framework for decentralized planning will depend on the degree to which local authorities can collaborate with other local actors in the wind power planning. The case serves as an interesting example of the relationship of institutional design to process design and of the sometimes complicated nature of organizational arrangements; those arrangements that provide for interaction guiding for actors from across sectors and interests are likely to be successful in promoting wind power development. A network management approach would have expected this to be the case and would have provided theoretical grounding for this conclusion.

\section{Managing networks in renewable energy development: outlining a future research agenda}

The most common approach employed by governments to develop renewable energy has been to deploy policy instruments that alter the perceived rate-of-return (pay-off) on future investment and thus create economic incentives for such development. However, acknowledging the importance of efficient collaboration processes requires a stronger focus on the composition and the performance of the actor networks and the different ways of managing these processes. If policy makers simply aim at reducing investment risks (e.g., through feed-in premiums to wind power generation), the uncertainties facing key actors will be reduced, but important network coordination problems may remain. For instance, a broadening of the network implies increased complexity as technical, economic and social issues become more intertwined, and unless actors (e.g. network managers) take steps to broaden the actor network, the lack of interpretative knowledge may remain undeveloped and, in turn, lead to poor and/or delayed decision-making. The point of departure for this article was therefore two-fold: first, that a multi-level governance-and network-perspective is critical in order to understand the outcomes of renewable energy development processes and secondly, that the issue of how networks in these processes are managed should be better acknowledged. The network approach delineates the social system, defines the main analytical unit, and offers a theoretical notion combining both agency and structure, suggesting that certain features of the network influence the development of renewable energy resources. The network management approach accounts for and categorizes governance strategies by how these strategies influence the network structure, substance and process.

This article has proposed an analytical framework for more systematically understanding the network management of renewable energy development, as well as the relationship of network management to institutional design. At a general level, the framework suggests that, in addition to state-level policy instruments (i.e. formal institutions), renewable energy outcomes are influenced by the complex interactions between different types of actors whose capabilities, preferences and perceptions are largely, but not completely, shaped by the institutionalized rules and norms within which they interact. Previous studies have been drawn upon in order to illustrate the empirical salience of this framework, as well as to demonstrate how previous studies would have benefitted from this framework by being able to more fully account for and theoretically integrate the empirical findings relevant to understanding renewable energy development.

One of the most evident conclusions from the studies reviewed is that there is variation between the governing institutions, as well as between the strategies employed to develop wind power within those institutions (see Tables 1 and 2). Previous research has shown that differences in wind power development outcomes also vary within similar, or even the same, institutional frameworks (i.e., within the same country, under the same national rules) (e.g., [77,98]). This suggests that whether and which network management strategies are employed will likely make a difference in network outcomes. The analytical framework developed in this article can therefore shed light on these issues. The framework enables the study of different types of strategies for network management, their interactions, as well as their relative importance under the same rules or institutional design. Our analysis provides several examples of how network managers can govern the collaboration process by means of encouraging key-actors' involvement, framing of goals, organizing committees, etc. (see Table 2). However, because empirical studies with the specific aim of studying institutional design and network management in the context of renewable energy development are mostly missing, there is currently no data necessary to make accurate assessments of the relative impacts of different rules and network strategies on policy outcomes. These are areas requiring further empirical investigation utilizing these perspectives, and the framework developed in this article could support such ambitions. 
In terms of the analytical framework - the concepts used here and how they function - there are a number of points to be made. The policies and institutions created at the regional and local levels are sometimes difficult to characterize, as they constitute institutions within which actors at the local level act, while also being created by actors from within the network itself. In addition, whether something can be considered a network management strategy or not depends greatly on how a given policy has been reached or how an instrument was implemented (e.g. what actors were involved or not, and in what way they were involved) as much as on what policy instrument was used. Thus, the focus of study becomes the process of setting goals and policies, making laws, etc., more than simply the content of these institutions, which has been well-addressed by previous studies.

On another note, when applying the network management framework to understanding empirical data, actions taken by network managers that affect network structure, substance and processes often represent the use of multiple strategies, as outlined within our framework. For example, creating an organization that helps actors coalesce around a goal-a network substance strategy-might also involve the activation of those actors-a network structure strategy. For this reason, it is useful to investigate specific actions by specific actors, and then define them nonexclusively as belonging to one or more categories of network management strategies. The same holds true for institutions. For example, rules that define who participates in a network may also define pay-off rules. Here again, defining particular rules according to the types of rules that they represent will likely prove a better and more accurate approach than defining rules according to the categories exclusively. On the theoretical level, this approach indicates that the categories of rules and strategies suggested are non-exclusive and perhaps in need of further theoretical elaboration and distinction.

The underlying puzzle of this article-how networks for renewable energy development can be managed within the context of given institutions-has been theoretically framed, although far from solved. Empirical studies explicitly employing this framework, that set out to gather data on networks and the network management strategies, will be necessary to enhance our knowledge of these matters. Specifically, we hope to inspire future research on two major questions.

First, what is the relationship between network characteristics, the quality of network processes, and network outcomes in cases of renewable energy development? The effect of networks on the function and performance of organizing processes, which has been addressed in prior research in other empirical areas, indicates a need for more research on this issue within the context of renewable energy development. For example, is a network that suffers from conflicts between developers and the local community structurally different than a network in which win-win situations have been achieved? What type of actor is most suited for the coordination function, and are shifts in leadership necessary, or problematic, over time? These lines of inquiry complement calls within the innovation system research for developing indicators to assess the strength of important innovation processes (e.g., [42]). While there are theories and likely hypotheses from network theory to build on, their relevance needs to be empirically examined within the context of renewable energy development.

Second, how can the evolution of networks be promoted? Here, the use and effectiveness of strategies for network management are explored. Are certain strategies more efficient than others, and under what circumstances? For instance, what strategies can be applied to create incentives for key actors to participate? How can possible deadlocks be handled and win-win situations negotiated? Finally, and related to this last question, the possible interactions between managing networks via institutional design and via pro- cess design should be examined. In this article, we have primarily treated institutional rules as exogenous influences on local network processes, but in some cases, process design strategies may also influence institutional change.

Only empirical studies with an explicit network management perspective connected to institutional design, as well as appropriate research designs, can answer the questions posed above. We particularly encourage the use of comparative designs in conducting these studies, with both cross-country comparisons and comparisons within countries. While the former approach is particularly suited for the purpose of examining the effects of different institutional constraints on the function and performance of networks, the latter approach enhances comparisons that isolate variations in national institutions and allow for studies on differences between networks and network management strategies operating in the same institutional context. Contemporary calls for a more sustainable society commonly assume - explicitly or implicitly - an increase in the amount of renewable energy. A common research agenda that acknowledges the importance of both institutions and networks-as well as the connections between them-and a research agenda that poses questions about how to manage networks in the context of renewable energy development is therefore not only appropriate, but necessary.

\section{Acknowledgments}

Financial support from the from the Swedish Energy Agency and the Swedish research council Formas is gratefully acknowledged, as are helpful research assistance and comments on the manuscript from Stefan Linde, Åsa Lindman, Daniel Nohrstedt and three anonymous reviewers. Any remaining errors reside solely with the authors.

\section{References}

[1] R. Agranoff, Inside collaborative networks: ten lessons for public managers, Public Adm. Rev. 66 (2006) 56-65 (Special Issue)

[2] R. Agranoff, M. McGuire, Collaborative Public Management: New Strategies for Local Governments, Georgetown University Press, Washington, DC, 2003.

[3] R. Agranoff, M. McGuire, Big questions in public network management research, J. Public Adm. Res. Theory 11 (3) (2001) 295-326.

[4] R. Agranoff, M. McGuire, Multinetwork management: collaboration and the hollow state in local economic policy, J. Public Adm. Res. Theory 8 (1) (1998) 67-91.

[5] I. Bache, M. Flinders (Eds.), Multi-Level Governance, Oxford Universtiy Press, Oxford, 2004.

[6] C. Beckman, P. Haunschild, Network learning: the effects of partner's heterogeneity of experience on corporate acquisitions, Adm. Sci. Q. 47 (2002) 92-124.

[9] M. Bolinger, Community Wind Power Ownership Schemes in Europe and Their Relevance to the United States, LBNL-48357, Lawrence Berkeley National Laboratory, Berkeley, California, 2001.

[11] S.P. Borgatti, M.G. Everett, J.C. Johnson, Analyzing Social Networks, Sage Publications, London, 2013.

[12] S.P. Borgatti, P.C. Foster, The network paradigm in organizational research: a review and typology, J. Manag. 29 (6) (2003) 991-1013.

[13] R.A. Boschma, Proximity and innovation: a critical assessment, Reg. Stud. 39 (1) (2005) 61-74.

[14] S. Breukers, M. Wolsink, Wind power implementation in changing institutional landscapes: an international comparison, Energy Policy 35 (2007) 2732-2750

[15] J.M. Bryson, B.C. Crosby, M.M. Middleton Stone, The design and implementation of cross-sector collaborations: propositions from the literature, Public Adm. Rev. 66 (2006) 44-55 (Special Issue).

[16] H. Bulkeley, Reconfiguring environmental governance: towards a politics of scale and networks, Polit. Geogr. 24 (2005) 875-902.

[17] R.S. Burt, The contingent value of social capital, Adm. Sci. Q. 42 (1997) 339-365.

[18] R.S. Burt, The network structure of social capital Research in Organizational Behaviour, vol. 22, JAI Press, Greenwich, CT, 2000, pp. 345-423.

[19] L. Butler, K. Neuhoff, Comparison of feed-in tariff: quota and auction mechanisms to support wind power development, Renew. Energy 33 (2008) 1854-1867.

[21] L. Carlsson, Policy networks as collective action, Policy Stud. J. 28 (3) (2000) $502-520$. 
[22] J.S. Coleman, Foundations of Social Theory, Harvard University Press, Cambridge, 1990.

[23] P. Cooke, Regional innovation systems clusters, and the knowledge economy, Ind. Corp. Change 10 (2001) 945-974.

[24] R. Cowell, Wind power and 'The planning problem': the experience of Wales, Eur. Environ. 17 (2007) 291-306.

[25] K. Dowding, Model or metaphor? A critical review of the policy network approach, Polit. Stud. 43 (1) (1995) 136-158.

[26] C. Daugbjerg, Linking policy networks and environmental policies: nitrate policy making in Denmark and Sweden 1970-1995, Public Adm. 76 (1998) 275-294.

[27] Department of Energy and Climate Change (UK), Delivering Community Benefits from Wind Energy Development: A Toolkit. A Report for the Renewables Advisory Board, Department of Energy and Climate Change, London, 2009.

[28] P. Del Rio, M. Bleda, Comparing the innovation effects of support schemes for renewable electricity technologies: a function of innovation approach, Energy Policy 50 (2012) 272-282

[29] P. Devine-Wright, Beyond NIMBYism: towards an integrated framework for understanding public perceptions of wind energy, Wind Energy 8 (2005) 125-139.

[30] J. Donahue, On Collaborative Governance. Corporate Social Responsibility Initiative Working Paper No. 2, John F. Kennedy School of Government, Harvard University, Cambridge, MA, 2004.

[31] T. Ejdemo, P. Söderholm, Wind power, regional development and benefit-sharing: the case of Northern Sweden, Renew. Sustain. Energy Rev. 47 (2015) 476-485.

[32] R.E. Elmore, Organisational models of social program implementation, in: M. Hill (Ed.), The Policy Process. A Reader, Second edition, Harvester Wheatsheaf, London, 1993, pp. 313-348.

[33] R.W. Gage, M.P. Mandell (Eds.), Strategies for Managing Intergovernmental Policies and Networks, Praeger, New York, 1990.

[34] M. Gargiulo, M. Benassi, Trapped in your own net? Network cohesion, structural holes and the adaptation of social capital, Organ. Sci. 11 (2000) $183-196$.

[35] S. Giest, Comparative analysis of Sweden's wind energy policy: the evolution of coordinated networks, J. Comp. Policy Anal. 4 (2015) 393-407.

[36] R. Hindmarsh, Wind farms and community engagement in Australia: a critical analysis for policy learning, East Asian Sci. Technol. Soc. Int. J. 4 (2010) 541-563.

[37] B. Hjern, D.O. Porter, Implementation structures. A new unit of administrative analysis, in: M. Hill (Ed.), The Policy Process. A Reader, Harvester Wheatsheaf, London, 1993, pp. 248-265.

[38] L. Hooghe, G. Marks, Unraveling the central state, but how? Types of multi-level governance, Am. Polit. Sci. Rev. 97 (2) (2003) 233-243.

[39] S.E. Human, K.G. Provan, Legitimacy building in the evolution of small-firm multilateral networks: a comparative study of success and demise, Adm. Sci. Q. 45 (2) (2000) 327-365.

[40] S.E. Human, K.G. Provan, An emergent theory of structure and outcomes in small-firm strategic manufacturing networks, Acad. Manag. J. 40 (2) (1997) 368-403.

[41] International Energy Agency (IEA), Tackling Investment Challenges in Power Generation, OECD, Paris, 2007.

[42] S. Jacobsson, A. Bergek, Innovation system analyses and sustainability transitions: contributions and suggestions for research, Environ. Innov. Soc. Transit. 1 (2011) 41-57.

[43] S. Jacobsson, A. Johnson, The diffusion of renewable energy technology: an analytical framework and key issues for research, Energy Policy 28 (2000) 625-640.

[44] A. Jobert, P. Laborgne, S. Mimler, Local acceptance of wind energy: factors of success identified in French and German case studies, Energy Policy 35 (2007) 2751-2760.

[45] C. Jones, W.S. Hesterly, S.P. Borgatti, A general theory of network governance: exchange conditions and social mechanisms, Acad. Manag. Rev. 22 (1997) 911-945.

[46] G. Jordan, Sub-governments policy communities and networks, refilling the old bottles? J. Theor. Polit. 2 (3) (1990) 319-338.

[47] J. Khan, Wind power planning in three Swedish municipalities, J. Environ. Plan. Manag. 46 (4) (2003) 563-581.

[48] I. Khorsand, C. Kormos, E.G. MacDonald, C. Crawford, Wind energy in the city: an interurban comparison of social acceptance of wind energy projects, Energy Res. Soc. Sci. 8 (2015) 66-77.

[49] W.J.M. Kickert, E.-H. Klijn, J.F.M. Koppenjan (Eds.), Managing Complex Networks: Strategies for the Public Sector, Sage Publications, London, 1997.

[50] E.-H. Klijn, B. Steijn, J. Edelenbos, The impact of network management on outcomes in governance networks? Public Adm. 88 (4) (2010) 1063-1082.

[51] E.-H. Klijn, Designing and managing networks: possibilities and limitations for network management, Eur. Polit. Sci. 4 (2005) 328-339.

[52] E.-H. Klijn, J. Koppenjan, K. Termeer, Managing networks in the public sector: a theoretical study of management strategies in policy networks, Public Adm. 73 (1995) 437-454.

[53] D. Knoke, Political Networks. The Structural Perspective, Cambridge University Press, Cambridge, 1990.

[54] J.F.M. Koppenjan, E.-H. Klijn, Managing Uncertainties in Networks, Routledge, London, 2004
[55] J.K. Lemming, P.E. Morthorst, N.-E. Clausen, Offshore Wind Power. Experiences, Potential and Key Issues for Development, Riso National Laboratory, Technical University of Denmark, 2007.

[56] D. Leonard-Barton, Wellsprings of Knowledge: Building and Sustaining the Sources of Innovation, Harvard Business School Press, Boston, 1995.

[59] D. Marsh, M. Smith, Understanding policy networks: towards a dialectical approach, Polit. Stud. 48 (March) (2000) 4-21.

[60] M. McGuire, R. Agranoff, The limitations of public management networks, Public Adm. 89 (2) (2011) 265-284.

[61] K.J. Meier, L.J. O'Toole Jr., Managerial strategies and behaviour in networks: a model with evidence from U.S. public education, J. Public Adm. Res. Theory (2001) 271-293.

[62] P. Menanteau, D. Finon, M. Lamy, Prices versus quantities: choosing policies for promoting the development of renewable energy, Energy Policy 31 (2003) $799-812$.

[63] N. Meyer, European schemes for promoting renewables in liberalised markets, Energy Policy 31 (2003) 665-676.

[64] C. Mitchell, D. Bauknecht, P. Connor, Effectiveness through risk reduction: a comparison of the renewable obligation in England and Wales and the feed-in system in Germany, Energy Policy 34 (2006) 297-330.

[65] A. Nadai, "Planning", "Siting" and the local acceptance of wind power: some lessons from the French case, Energy Policy 35 (2007) 2715-2726.

[66] A. Nadai, O. Labussiere, Wind power planning in France (Aveyron): from state regulation to local planning, Land Use Policy 26 (2009) 744-754.

[67] M. Nilsson, K. Eckerberg, Environmental Policy Integration in Practice. Shaping Institutions for Learning, Earthscan, London, 2009.

[68] D. North, Institutions, Institutional Change and Economic Performance, Cambridge University Press, Cambridge, 1990.

[69] E. Ostrom, Understanding Institutional Diversity, Princeton University Press, Princeton, 2005.

[70] E. Ostrom, S. Crawford, Classifying rules, in: E. Ostrom (Ed.), Understanding Institutional Diversity, Princeton University Press, Princeton, 2005, pp. $186-215$.

[71] E. Ostrom, R. Gardner, J. Walker, Rules, games, \& common-pool resources, The University of Michigan Press, Ann Arbor, 1994.

[72] L.J. O’Toole Jr., Treating networks seriously: practical and research-based agendas in public administration, Public Adm. Rev. (1997) 45-52.

[73] L.J. O’Toole Jr., K.J. Meier, Modeling the impact of public management: implications of structural context, J. Public Adm. Res. Theory 9 (4) (1999) 505-526.

[74] L.J. O’Toole Jr., K.J. Meier, Public management in intergovernmental networks: matching structural networks and managerial networking, J. Public Adm. Res. Theory 14 (4) (2004) 469-494.

[75] Y. Parag, J. Hamilton, V. White, B. Hogan, Network approach for local and community governance of energy: the case of Oxfordshire, Energy Policy 62 (2013) 1064-1077.

[76] Y. Parag, Who governs the air we breathe? Lessons from Israel's industrialist covenant, J. Environ. Policy Plan. 10 (2) (2008) 133-152.

[77] M. Pettersson, K. Ek, K. Söderholm, P. Söderholm, Wind power planning and permitting: comparative perspectives from the Nordic countries, Renew. Sustain. Energy Rev. 14 (2010) 3116-3123.

[78] M. Pettersson, P. Söderholm, Reforming wind power planning and policy: experiences from the Nordic countries, CESifo DICE Rep. J. Inst. Comp. 4 (Winter) (2011) 50-54.

[79] J. Pierre, G.B. Peters, Governing Complex Societies-Trajectories and Scenarios, Palgrave McMillan, Baingstoke, 2005.

[80] W.W. Powell, Neither market nor hierarchy: network forms of organization, Res. Org. Behav. 12 (1990) 295-336.

[81] K.G. Provan, B.H. Milward, A preliminary theory of interorganizational network effectiveness: a comparable study of four community mental health systems, Adm. Sci. Q. 40 (March) (1995) 1-33.

[82] K.G. Provan, B.H. Milward, Do networks really work? A framework for evaluating public-sector organizational networks, Public Adm. Rev. 61 (July/August) (2001) 414-423.

[83] K.G. Provan, P. Kenis, Modes of network governance: structure, management, and effectiveness, J. Public Adm. Res. Theory 18 (2) (2008) 229-252.

[84] D. Reiche, M. Bechberger, Policy differences in the promotion of renewable energies in the EU member states, Energy Policy 32 (2004) 843-849.

[85] R.K. Rethemeyer, D.M. Hatmaker, Network management reconsidered: an inquiry into management of network structures in public sector service provision, J. Public Adm. Res. Theory 18 (4) (2008) 617-646.

[86] R.A.W. Rhodes, Understanding Governance: Policy Governance, Reflexivity and Accountability, Open University Press, Philadelphia, 1997.

[87] S. Ruggiero, T. Onkila, V. Kuittinen, Realizing the social acceptance of community renewable energy: a process-outcome analysis of stakeholder influence, Energy Res. Soc. Sci. 4 (2014) 53-63.

[88] P.A. Sabatier, H.C. Jenkins-Smith, The advocacy coalition framework: an assessment, in: A. Paul Sabatier (Ed.), Theories of the Policy Process, Westview Press, Boulder, Colorado, 1999.

[89] A. Sandström, Ö. Bodin, B. Crona, Network governance from the top: the case of ecosystem-based coastal and marine management, Mar. Policy 55 (2015) 57-63.

[90] A. Sandström, B. Crona, Ö. Bodin, Legitimacy in co-management: the impact of preexisting structures, social networks and governance strategies, Environ. Policy Gov. 24 (1) (2014) 60-76. 
[91] A. Sandström, L. Carlsson, The performance of policy networks: the relation between network structure and network performance, Policy Stud. J. 36 (4) (2008) 497-524.

[92] A. Sandström, H. Ylinenpää, Research, industry and public sector co-operation. A dynamic perspective, Int. J. Innov. Reg. Dev. 4 (2) (2012) 144-159.

[93] M. Schneider, J. Scholz, M. Lubell, D. Mindruta, M. Edwardsen, Building consensual institutions: networks and the national estuary program, Am. J. Polit. Sci. 47 (January) (2003) 143-158.

[94] D.A. Siegel, Social networks and collective action, Am. J. Polit. Sci. 53 (1) (2009) 122-138.

[95] J. Szarka, Why is there no wind rush in France? Eur. Environ. 17 (2007) 321-333.

[96] M. Thatcher, The development of policy network analyses. From modest origins to overarching framework, J. Theor. Polit. 10 (4) (1998) 389-416.

[97] A.-M. Thomson, J.L. Perry, Collaboration processes: inside the black box, Public Adm. Rev. 66 (2006) 20-32 (Special Issue).

[98] D. Toke, S. Breukers, M. Wolsink, Wind power deployment outcomes: how can we account for the differences? Renew. Sustain. Energy Rev. 12 (4) (2008) 1129-1147.
[99] D. Toke, Explaining wind power planning outcomes: some findings from a study in England and Wales, Energy Policy 33 (2005) 1527-1539.

[100] G. Verbong, F.W. Geels, R. Raven, Multi-niche analysis of dynamics and policies in Dutch renewable energy innovation journeys (1970-2006): hyper-cycles, closed networks and technology-focused learning, Technol. Anal. Strat. Manag. 20 (5) (2008) 555-573.

[101] G. Walter, Determining the local acceptance of wind energy projects in Switzerland: the importance of general attitudes and project characteristics, Energy Res. Soc. Sci. 4 (2014) 78-88.

[102] C.M. Weible, P.A. Sabatier, Coalitions, science, and belief change: comparing adversarial and collaborative policy subsystems, Policy Stud. J. 37 (2) (2009) $195-212$.

[103] M. Wolsink, Wind power and the NIMBY-myth: institutional capacity and the limited significance of public support, Renew. Energy 21 (2000) 49-64.

[104] H. Ylinenpää, Triple helix co-operation in a cross-border perspective-experiences from an interactive research project, in: C. Karlsson, P. Flensburg, S.-Å Hörte (Eds.), Knowledge Spillovers and Knowledge Management, Edward Elgar, Northampton, 2004, pp. 347-369. 